\title{
Ética y experiencia universitaria: el papel de la libertad de cátedra en el aprendizaje ético y sus amenazas
}

\author{
Ethics and university experience: academic \\ freedom's role on learning ethics and its threats
}

Hugo Saúl Ramírez García

Profesor a tiempo completo.

Facultad de Derecho de la Universidad Panamericana.

Campus Ciudad de México.

Investigador Nacional Nivel II del Sistema Nacional de Investigadores, CONACYT.

E-mail: hsramire@up.edu.mx

\begin{abstract}
Resumen: La hipótesis que se pretende demostrar en este trabajo es que la autocensura, motivada por lo políticamente correcto, puede obstaculizar el ejercicio la libertad de cátedra y en ese sentido limitar el papel que actualmente se reconoce al docente a favor del aprendizaje ético de los alumnos. Con este objetivo se examina a la universidad como ambiente propicio para el aprendizaje ético y el papel del docente dentro de ésta. En torno a este último punto me planteo una respuesta para la pregunta ¿a partir de qué posición debe el docente abordar las cuestiones socialmente controvertidas en un aula universitaria? y, finamente, se reflexionó sobre el valor práctico de la libertad de cátedra y su relación con la corrección política.

Palabras clave: aprendizaje ético, debate moral, imparcialidad, libertad de catedra, corrección política, autocensura.
\end{abstract}

\footnotetext{
Abstract: This article tries to demonstrate that self-censorship, motivated by the politically correctness, can undermine academic freedom and in that sense limit the professor's role on teaching ethics. Aiming towards this goal, it examines the university as an appropriate environment for ethical learning and the lecturer's role within it. In relation to this last point: the position from which controversial issues should be address in the university, as well as the practical value of academic freedom and its relationship with political correctness are studied.
} 
Keywords: ethical learning, moral debate, non-bias, academic freedom, political correctness, self-censorship.

\section{Ética y experiencia universitaria: el papel de la libertad de cátedra en el aprendizaje ético y sus amenazas.}

Ethics and university experience: academic freedom's role on learning ethics and its threats.

\section{Introducción}

A partir de la crisis del positivismo jurídico ${ }^{1}$ se han ampliado las oportunidades para comprender al Derecho fuera de los márgenes de lo estrictamente formal y preguntarnos, entre otras cosas, de qué manera se vincula la experiencia jurídica con otras dimensiones de la vida práctica, por ejemplo con la moral y con la ética.

Siguiendo esta línea de reflexión pueden ser identificados al menos tres puntos de contacto entre derecho, moral y ética: (a) uno relativo al fundamento último del deber de ajustar la conducta propia a lo prescrito por una norma jurídica positiva; (b) otro relacionado al componente sustantivo-axiológico de la validez de una norma jurídica positiva; (c) finalmente otro vinculado al reconocimiento de la importancia de la virtud moral del operador jurídico para la viabilidad del Estado de Derecho, a través de una deontología jurídica auténticamente vivida. Los dos primeros puntos fueron sintetizados por Robert Spaemann quien, con meridiana claridad, sostuvo que la validez del deber moral de ajustar la propia conducta a lo prescrito por una norma jurídica positiva depende, en último término, de que tales normas satisfagan determinadas condiciones morales $^{2}$.

Por otra parte, la deontología jurídica realmente vivida es hoy reconocida como una de las más importantes condiciones de viabilidad para el Estado de Derecho. En efecto, si la participación en él no se limita al mero cumplimiento del principio de legalidad, sino a la realización de una serie de valores, bienes y fines que subyacen a las normas jurídico positivas, resulta innegable que sus operadores requerirán de una serie de virtudes que les habiliten para llevar a cabo los actos con los cuales honren su compromiso con esos valores, bienes y fines ${ }^{3}$.

\footnotetext{
${ }^{1}$ Para una explicación de este fenómeno académico, véase: (SERNA, 2006, 13-45).

2 (Cfr., SPAEMANN, 2000, 113)

3 (Cfr., APARISI, 2006, 366-367); (Cfr., AGUILÓ, 2009, 538-539).
} 
En esta ocasión centraré mis reflexiones en torno al último punto, concretamente al contexto de la formación universitaria donde los profesionistas en general, y los abogados en particular, tienen la oportunidad de integrarse a una comunidad académica para formarse a través de la adquisición de un conocimiento experto, así como para continuar y completar el complejo proceso de maduración que les lleve a ser razonadores prácticos independientes. He tomado esta expresión del pensamiento de Alasdair MacIntyre con el propósito adicional de poner énfasis en el hecho de que el florecimiento humano como razonador práctico independiente no es el resultado de una labor que llevemos a cabo de manera aislada y solitaria; al contrario, en ella requerimos ineludiblemente de la compañía y asistencia de otros. Esta idea será medular para las reflexiones que pretendo desarrollar en el presente artículo, y dada su centralidad, considero oportuno la cita directa a MacIntyre en su Animales racionales y dependientes:

"Llegar a ser un auténtico razonador práctico independiente es un logro, pero es un logro para el que los demás también han contribuido de manera esencial (...) (Para que un ser humano llegue a desarrollar sus capacidades como razonador práctico independiente) necesita de los demás de varias maneras: los necesita para mantener relaciones que estimulen la capacidad para evaluar, modificar o rechazar sus propios juicios prácticos, la capacidad para preguntar si lo que considera que son buenas razones para actuar sean realmente buenas razones; los necesita para desarrollar la capacidad de imaginar con realismo futuros alternativos posibles, de modo que pueda elegir racionalmente entre ellos; los necesita para adquirir la capacidad de distanciarse de sus deseos, para poder indagar racionalmente lo que es necesario para buscar su propio bien aquí y ahora y orientar sus deseos y, en caso de ser necesario, reeducarlos para alcanzar el bien". (MACINTYRE, 2000, 100-101)

Con lo anterior en mente me propongo ahondar en una propuesta que juzgo muy interesante: se trata de hacer del espacio universitario una oportunidad para el aprendizaje ético, ambos indispensables en el florecimiento moral del ser humano al que hemos hecho referencia. El núcleo de esta propuesta la he localizado en un artículo escrito por Miquel Martínez Martín, María Rosa Buxarrais Estrada y Francisco Esteban Bara, publicado en el número 29 de la Revista Iberoamericana de Educación, dedicado al tema de la Ética y la formación universitaria. 
En la primera parte del artículo tendré en cuenta los que a mi juicio son los elementos más importantes de esta propuesta, centrando mi interés sobre la figura del docente; particularmente en la redefinición de su papel: no solo como quien acompaña al estudiante universitario en la adquisición de un conocimiento especializado y habilidades concretas, sino ahora como un protagonista en la configuración del ambiente adecuado para el aprendizaje ético.

La segunda parte se centra en la libertad de cátedra. Ahí pretendo realizar algunos comentarios en torno a esta libertad y a las incidencias que sobre ella podría tener la corrección política. Llegado el momento quisiera mostrar cómo la autocensura, motivada por lo políticamente correcto, puede minar la libertad de cátedra y, en ese sentido, limitar el papel que se reconoce al docente en el aprendizaje ético. Algunas ideas, con afán de recopilación, harán las veces de apartado conclusivo.

\section{La experiencia universitaria como oportunidad para el aprendizaje ético}

Martínez, Buxarrais y Esteban postulan un diagnóstico que me parece acertado cuando afirman que el ciudadano del siglo XXI, quizás más que el de otras épocas, va a enfrentarse a dilemas prácticos complejos; por ejemplo, en los que el cauce de acción a elegir tendrá efectos próximos y remotos, tanto en sentido espacial como temporal ${ }^{4}$. En efecto, como ha sido advertido agudamente por autores como Hans Jonas, nuestra época se caracteriza por la presencia de actos con efectos remotos, es decir, conductas que, en el marco del progreso tecnológico, se llevan a cabo en el momento presente pero cuyos efectos, en muchas ocasiones dañinos, no se manifiestan sino después de transcurrido un largo periodo de tiempo ${ }^{5}$. Frente a tal realidad urge, entre otras cosas, la renovación semántica del concepto de responsabilidad.

Por otro lado, un segmento adicional del diagnóstico que presentan nuestros autores nos advierten acerca de los efectos negativos que siguen al subjetivismo radical $^{6}$ en el plano de la praxis; es decir, cierta interpretación de la autonomía que la caracteriza

\footnotetext{
4 (Cfr., MARTÍNEZ et al., 2002, 24)

${ }^{5}$ Como lo explica el propio Hans Jonas: "la capacidad tecnológica ha transformado lo que antes eran juegos experimentales y quizás instructivos de la razón especulativa en diseños competitivos de proyectos realizables. Y al elegir entre ellos hemos de elegir entre extremos con efectos remotos y en su mayor parte desconocidos. Lo único que podemos conocer de ellos es su carácter extremo, o sea: que afectan la condición total de la naturaleza en nuestro planeta”. (JONAS, 1995, 55).
}

${ }^{6}$ (Cfr., MARTÍNEZ et al., 2002, 24) 
fundamentalmente como simple capacidad para elegir ${ }^{7}$. Frente a ello, y a mi juicio con acierto, defienden una aproximación a la autonomía como aquella capacidad del sujeto agente para incorporar existencialmente unos valores a su propio repertorio cognitivo, de una forma significativa ${ }^{8}$. Dicho con otros términos, proponen entender a la autonomía como la aptitud para traducir el lenguaje general y abstracto de los valores y de las normas que los expresan, en actos personales: concretos y específicos ${ }^{9}$.

De este panorama se desprende la necesidad urgente por repersonalizar la moralidad que, en términos de Zygmunt Bauman ${ }^{10}$, significa superar la desconfianza en el sujeto moral para que reasuma el protagonismo que le corresponde al momento de encarar los dilemas prácticos que se le presentan de manera cotidiana; esto es razón suficiente para realizar todos los esfuerzos que sean requeridos a fin de consolidar una auténtica formación ética, que procure el desarrollo y la optimización de las diferentes dimensiones de la personalidad moral de los sujetos.

Concretamente, Martínez, Buxarrais y Esteban señalan que el interés de su propuesta se dirige a la formación ética del sujeto que aprende en el contexto universitario; es decir, que el futuro egresado sepa lo que éticamente es o no correcto en el ejercicio de su profesión, pero además y sobre todo, que sepa comportarse guiado por ese conocimiento en cualquier contexto: como hijo, como compañero, como ciudadano, etcétera. A esto lo denominan "aprendizaje con enfoque ético"(MARTÍNEZ et al.,

\footnotetext{
${ }^{7}$ Esta lectura de la autonomía es deudora de la interpretación moderna de la libertad como manifestación inequívoca de la mayoría de edad moral del individuo, y en último término como antídoto frente al paternalismo. Como nos recuerda Jesús Ballesteros, en la medida en que el imperativo más relevante para el ejercicio de una libertad así entendida es el de no interferir en la libertad individual, cualquier otro se torna obstáculo para la consecución de la autosuficiencia del individuo para lograr su propia y excluyente felicidad: el aislamiento moral del individuo está servido. (Cfr., BALLESTEROS, 2000, 54-65).

8 (Cfr., MARTÍNEZ et al., 2002, 24)

${ }^{9}$ En línea con lo expuesto, Francesco Viola distingue entre dos sentidos del concepto autonomía: la autonomía personal y la moral. Ésta hace referencia a una propiedad estructural de la humanidad, gracias a la cual se configura un tipo o forma de vínculo entre el sujeto moral y el ethos; tal vínculo está caracterizado por la traducción del lenguaje y validez universal de una norma, en lenguaje personal; dicho con otros términos, la autonomía permite el traslado de las razones abstractas de la norma, a las razones concretas del acto personal. (Cfr., VIOLA, 1998, 339-340)

10 Textualmente afirma Bauman: "Más que reiterar que no habría individuos morales si no fuera por la labor de capacitación y supervisión de la sociedad, cada vez comprendemos mejor que debe ser la capacidad moral del ser humano lo que lo hace capaz de formar sociedades y, contra todo, asegurar su supervivencia”. (Cfr., BAUMAN, 2005, 40-41)
} 
2002, 26), o también aprendizaje ético; tomando ideas de Alejandro Llano, igualmente podría denominarse como pedagogía para un humanismo cívico ${ }^{11}$.

¿En qué consiste tal educación con mayor precisión? Debemos aclarar que no equivale solo a la acumulación de conocimientos teóricos; por ejemplo aquellos que permitan distinguir entre el eudemonismo y el utilitarismo. El aprendizaje ético que postulan nuestros autores procura producir cambios reales en los comportamientos de las personas, derivados de la práctica misma. Es decir, se propone que los sujetos actúen basados en una reflexión ética seria que conduzca a los mejores efectos morales, gracias al aprendizaje existencial de valores, al desarrollo y mejora de los niveles de razonamiento moral y al encuentro con modelos prácticos a través de la imitación o del relato.

Ahora bien, para que el aprendizaje ético tenga contenido y sentido es necesario reconocer un zócalo axiológico mínimo a partir del cual se desarrolle. En efecto, si bien nuestros autores no pretenden la transmisión de un determinado sistema de valores, reconocen la necesidad de que la justicia, la igualdad, la libertad, la solidaridad, el respeto, la tolerancia activa y la actitud de diálogo, sean apreciados como tales, así como denunciada su ausencia o vulneración. Lo anterior se fundamenta en la convicción de que estamos en un mundo donde el desarrollo de esas dimensiones axiológicas es tan necesario como aprender a leer y a escribir. Social y culturalmente nuestra sociedad necesita personas hábiles para identificar, experimentar y apreciar valores; en saber organizar su mundo para ser protagonistas y dueñas de sus acciones, entrenadas en el ejercicio de la responsabilidad que les corresponde al ser conscientes de que son ellas las que están decidiendo sobre su comportamiento, el cual tiene efectos en ellas y en los demás $^{12}$.

Hasta aquí la explicación sobre el aprendizaje ético: su objeto y objetivos; ahora es necesario hacer referencia a las condiciones que lo propician.

Sobre esta cuestión Martínez, Buxarrais y Esteban establecen que hará falta integrar en los escenarios de aprendizaje en los que se forma el estudiante universitario situaciones

\footnotetext{
${ }^{11}$ Para que se entienda esta idea, no me resisto a citar a Alejandro Llano, quien describe al humanismo cívico como aquella concepción de la sociedad que se caracteriza, entre otras cosas, por el protagonismo de las personas reales y concretas, que toman conciencia de su condición de miembros activos y responsables de la sociedad y procuran participar eficazmente en la consecución de bienes comunes. (Cfr., LLANO, 1999, 15) Entonces, una pedagogía para el humanismo cívico es una estrategia de enseñanza que nos habilita para habitar en una sociedad como la descrita.
}

12 (Cfr., MARTÍNEZ et al., 2002, 29-30) 
reales que permitan estimular el desarrollo de capacidades morales. Concretamente se trata de generar, de forma sistemática, las condiciones que para que el universitario mejore en planos como el del autoconocimiento, la autonomía y la autorregulación, facilitando así el incremento en su comprensión crítica y capacidad de diálogo. En pocas palabras robusteciendo su razonamiento moral. Más aún, la propuesta de nuestros autores busca que el estudiante universitario sea capaz de transformar el medio que le es propio en otro mejor, gracias al tipo de actos que lleva a cabo cotidianamente ${ }^{13}$.

\section{EI rol reconfigurado del docente universitario como pieza clave del aprendizaje ético}

Un factor estratégico para que el ambiente universitario sea fecundo al aprendizaje ético que venimos glosando es el papel del docente que para estos efectos debe reconfigurarse o, mejor dicho, enriquecerse.

Martínez, Buxarrais y Esteban señalan que, por un lado, el nuevo docente es el profesional encargado de enseñar a aprender la ciencia, de enseñar a gestionar el conocimiento de una forma significativa y con sentido personal para el estudiante. Pero adicionalmente es el encargado de imprimir a los contenidos que enseña el enfoque ético que hará que el estudiante sea un experto profesional y un buen ciudadano ${ }^{14}$.

¿Y cómo puede el docente llevar a cabo esta renovada función, así como cumplir con las responsabilidades ahí implicadas? Comprometiéndose moralmente con su tarea formadora, es decir, no se trata tanto de ser un experto competente: hay que querer serlo de tal forma la acción académica no se limite al hecho de producir ciencia y de transmitirla, sino que sea una acción responsable y con compromiso moral hacia la formación integral del alumno.

En este orden de ideas, el compromiso moral del docente se realiza cuando cumple con el principio de respeto del estudiante qua persona. A su vez, este principio se especifica en diferentes deberes que dan sentido a los actos del académico en las formas concretas de relación con los estudiantes. Éstas pueden clasificarse en tres tipos: las de carácter lectivo, como responsable de enseñar una asignatura; las de evaluador del aprendizaje alcanzado por el estudiante; y las de tutor o persona de referencia, tanto para consultas sobre el contenido de lo que enseña, como para las de carácter más general o incluso

\footnotetext{
${ }^{13}$ (Cfr. Ibídem, 30)
}

${ }^{14}$ (Cfr. Ibídem, 34) 
personal del estudiante ${ }^{15}$. El principio general de respeto a la persona del estudiante puede concretarse, en el primer caso, a través del cumplimiento del deber de diligencia, lo que supone ocuparse de su propia formación en forma permanente; y en el de veracidad, que obliga al profesorado, por su función docente e investigadora, a comprometerse con el reconocimiento de las diferencias entre verdad y falsedad y el valor superior de la primera sobre la última. En el segundo caso el principio se concreta en el cumplimiento del deber de no discriminación, objetividad y ecuanimidad. En el tercero, respetando el deber de secreto profesional, que supone el compromiso de la discreción en relación con todo aquello que no es preciso divulgar.

Pero en todos los casos, nos recuerdan Martínez, Buxarrais y Esteban, debe tenerse en cuenta uno de los principios más complejos y a la vez más importantes para el aprendizaje ético en el ámbito universitario, a saber, el de desinterés. Según los autores, consiste en que el docente no ejerza dominio de ningún tipo sobre el estudiante, abusando de la relación asimétrica que mantiene con él, dada la diferencia de conocimiento, experiencia, habilidades o recursos ${ }^{16}$.

El cumplimiento de este imperativo redunda en la promoción de la autonomía del estudiante, del uso del diálogo y de la consideración a la diferencia de criterio, e incluso de interpretación respecto a la veracidad o no de lo que afirma y se propone como cierto por parte del profesorado. En definitiva el docente debe ser plenamente consciente de que quien mantiene una actitud de tensión hacia lo verdadero sabe que se trata de algo que no puede imponerse. De lo contrario incurriría en una actitud manipuladora; en efecto, dentro del ámbito educativo la manipulación es un proceso de reduccionismo del ser humano diametralmente opuesto a la auténtica educación, la cual es un proceso de mejora personal. Con mayor detalle:

"La manipulación se apoya en la ambigüedad; la educación en la claridad de ideas. La manipulación fomenta la incongruencia; la educación los comportamientos humanos congruentes (...). La manipulación es una tiranía solapada que instrumentaliza a la persona humana al servicio de lo lucrativo, o de lo ideológico; la educación es un servicio de mejora que finaliza su acción en la persona, respetando su modo de ser”. (OTERO, 1990, 33-34)

\footnotetext{
15 (Cfr. Ibídem, 35)
}

16 (Cfr., Idem.) 
Ahora bien, particular interés para mis reflexión suscita el caso de cuestiones socialmente controvertidas; es decir, aquellos dilemas de naturaleza pública sobre los que se ha generado una peculiar sensibilidad social, y que en no pocas ocasiones suponen posturas radicalmente enfrentadas. Se trata de oportunidades inmejorables para la reflexión ética, ya que la dificultad de su resolución es al mismo tiempo una fuerza que impele a que la duda y confusión queden despejadas a través del intercambio de puntos de vista que trazan un itinerario que va del plano de las razones al mundo de la acción, y de éste de nuevo a aquél (SANDEL, 2013,39), o viceversa.

Concretamente, nuestros autores advierten sobre la existencia de modos de tratar tales dilemas que generan aprendizaje ético favoreciendo una construcción autónoma y racional de valores en la persona del estudiante, y otros que conducen a posiciones solo subjetivas sin más fundamento que las justifique. En este orden de ideas instan a reflexionar sobre las pautas que regulan y orientan la forma de proceder para el docente, evitando que la autoridad moral y científica que pueda tener se convierta en factor que genere dependencia, pérdida de perspectiva crítica o falta de interés por conocer otras formas de aproximación y valoración para tales problemas.

En particular Martínez, Buxarrais y Esteban sostienen que, en línea con el principio de desinterés previamente descrito, la forma de abordar las cuestiones socialmente controvertidas por un docente debe ser desde posiciones de neutralidad $^{17}$.

Pero, ¿debe ciertamente ser así? Hasta ahora puedo declarar mi adhesión a la mayoría de las ideas presentadas por los multicitados autores en torno al aprendizaje ético en el ámbito universitario; sin embargo respecto de esta última tesis confieso importantes dudas y discrepancias. Me parece que debe ser el principio de imparcialidad y no la neutralidad lo que debe guiar la actitud del docente cuando trata cuestiones socialmente controvertidas en su cátedra, si lo que se pretende es que colabore realmente en el aprendizaje ético o pedagogía cívica de los alumnos.

A mi juicio, en el contexto de un aula universitaria, el docente puede o incluso debe explicitar sus puntos de vista respecto de las cuestiones socialmente controvertidas, si previamente ha puesto en contacto al alumno con el estado de la cuestión de manera exhaustiva. Es decir, debe exponer de manera clara y objetiva todas las posiciones que giran en torno al dilema; hecho esto, la libertad de cátedra habilita al docente para exponer su posicionamiento frente al mismo: con ello ha sido imparcial, pero al mismo

${ }^{17}$ (Cfr., MARTÍNEZ et al., 2002, 35) 
tiempo no ha sido neutral. Como nos recuerda Isabel Trujillo, es posible distinguir entre imparcialidad y neutralidad. La neutralidad significa abstención del juicio, mientras que la imparcialidad es un atributo de la estructura del juicio autoritativo que implica tomar partido siempre y cuando se cumplan una serie de deberes y condiciones como la objetividad, el desapasionamiento, en definitiva, todo aquello que impide favorecer por interés o simpatía a alguna de las partes ${ }^{18}$.

Con este modo de proceder fundado en la imparcialidad, el docente ha manifestado valores éticos como la honestidad y la coherencia intelectual. Es decir, no se ha limitado a exponer su opinión sino que, al tomar postura respecto del dilema, participa y exhibe los bienes internos de la práctica del diálogo moral. Tales bienes muestran todo su valor cuando nos ayudan a evitar que la vida moral, con sus dilemas y problemas, se limite a la realización congruente de prejuicios personales o compartidos. Como lo expone Michael Sandel:

"Si la reflexión moral consiste en perseguir la concordancia entre los juicios que hacemos y los principios a los que nos adherimos, ¿cómo puede una reflexión de esa naturaleza conducirnos a la justicia y a la verdad moral? Aunque lográsemos, en el curso de una vida, que nuestras intuiciones morales concordasen con los principios con los que nos comprometemos, ¿qué confianza podríamos tener en que el resultado no fuese más que una madeja de prejuicios congruentes? La respuesta es que la reflexión moral no es una empresa solitaria, sino un empeño público. Requiere un interlocutor (...); no podemos descubrir el significado de la justicia o la mejor manera de vivir por medio solo de la introspección". (SANDEL, 2013, 39-40)

Una pieza clave en el argumento que he expuesto es el del alcance y ejercicio de la libertad de cátedra. Quisiera, a continuación, ahondar un poco más sobre el significado práctico de tal libertad y, una vez hecho esto, centrar la atención sobre una amenaza que actualmente se cierne sobre su ejercicio que redundaría, desde mi punto de vista, en un perjuicio para el aprendizaje ético que venimos comentando.

${ }^{18}$ (Cfr., TRUJILLO, 2007, 69-71) 


\section{El ejercicio de la libertad de cátedra y el imperativo de corrección política}

IV.a El valor práctico de la libertad de cátedra

Respecto de la libertad de cátedra se han realizado magníficas exposiciones dogmáticas. Tal vez una de las más destacadas e influyentes ha sido la realizada por Rudolf Smend, quien la asocia como contenido de la libertad de expresión y ciencia, de forma específica como libertad para divulgar el conocimiento ${ }^{19}$. Sobre la libertad de cátedra quisiera centrarme, de forma breve, en tres puntos específicos: (a) en el origen de tal libertad; (b) en su alcance y límites; (c) finalmente en el valor ético que pude reconocerse a su ejercicio.

(a) El derecho de los académicos a la libertad de cátedra se origina formalmente como exigencia jurídica en la doctrina alemana, en el marco de la universidad humboldtiana, como un modo de impedir que desde el Estado se interviniera en lo que los profesores investigaban y enseñaban ${ }^{20}$.

Desde que fue reconocida institucionalmente, la libertad de cátedra manifiesta un significado práctico fundamental con el que se pretende garantizar que la función desplegada por los docentes universitarios no se encuentre condicionada al influjo del poder político, evitando que la universidad sea un mero instrumento de adoctrinamiento al servicio de la ideología política existente en un determinado momento, y que la ciencia asuma un carácter oficial ${ }^{21}$.

A lo largo de su historia institucional, son varios los documentos jurídicos, tanto constitucionales como de legislación secundaria, que la recogen. En este plano de derecho positivo cabe citar el fragmento con el cual el Tribunal Constitucional Español identificó su contenido, a principios de la década de 1980; los magistrados del mencionado tribunal señalaron que:

"El objeto de este derecho viene constituido por la libertad, por parte del docente, para poder transmitir, sin previa censura y sin ningún tipo de coacción, los criterios científicos, artísticos y culturales, que aquel considera cómo válidos desde una metodología determinada".

\footnotetext{
${ }^{19}$ (Vid., SMEND, 2005, 22 y siguientes)

${ }^{20}$ (Cfr., Ibídem, 27-28)

${ }^{21}$ (Cfr., AGUADO I CUDOLÀ, 2010, 3)
} 
Merece igual atención el alcance que tiene esta libertad según lo manifestado por Tribunal Superior de Justicia de Aragón en una sentencia de su Sala de lo Social:

"En cuanto libertad individual del docente, es en primer lugar y fundamentalmente, una proyección de la libertad ideológica y del derecho a difundir libremente los pensamientos, ideas y opiniones de los docentes en el ejercicio de su función. Consiste, por tanto, en la posibilidad de expresar las ideas o convicciones que cada profesor asume como propias con relación a la materia objeto de su enseñanza, presentando de este modo un contenido, no exclusivamente pero sí predominantemente negativo" (Sentencia del Tribunal Superior de Justicia de Aragón, Sala de lo Social, Sección 1ª núm. 1134/2004 de 30 septiembre [AS 2005\439]).

(b) A partir de estos antecedentes podemos afirmar, con Raúl Madrid, que la libertad de cátedra se traduce en la facultad multifacética atribuida a los académicos mediante la cual pueden desarrollar actividades de investigación, enseñanza y divulgación sobre cualquier tema que consideren de interés profesional sin riesgo ni amenaza de sanción alguna; excepto mediante la adecuada acreditación de incumplimiento de la ética profesional $^{22}$. En otras palabras, se trata del derecho a seguir las propias investigaciones hasta donde ellas conduzcan; y el de enseñar a los estudiantes de acuerdo con la mejor comprensión de la verdad ${ }^{23}$.

Margaret Somerville ofrece un enfoque que complementa lo anterior, ya que destaca el valor que cobra el reconocimiento y ejercicio de la libertad de cátedra como una pieza clave de la confianza que toda universidad necesita para cumplir uno de sus propósitos más relevantes: ser un espacio donde las ideas que tienen una peculiar e incluso peligrosa capacidad para dividir o polarizar, pueden ser discutidas en un contexto de respeto. En efecto, la libertad de cátedra actualiza un bien social porque configura el entramado institucional sobre el que se fundamenta un foro en el cual ideas y conocimientos pueden ser completa y abiertamente discutidos y probados sin temor o favor (SOMERVILLE, 2015, 50 y 79).

\footnotetext{
${ }^{22}$ En este sentido pueden considerarse como límites para el ejercicio de la libertad de cátedra, un par de criterios: El primero apunta al respeto a los demás derechos fundamentales, especialmente: el derecho al honor, a la intimidad y a la propia imagen. En segundo lugar, lo ocupa la hipótesis del abuso del derecho. Así, puede considerase como un ejercicio abusivo de la libertad de cátedra, aquella actitud del profesor que consiste en transmitir opiniones que no guardan relación con la materia impartida, o que son fruto exclusivamente de una opción ideológica transmitida con una exclusiva finalidad proselitista o denigratoria. Cfr., Ibídem, 3-4)

${ }^{23}$ (Cfr., MADRID, 2013, 356)
} 
Dicho esto, quisiera ocuparme brevemente del valor práctico de la libertad de cátedra. Recuperemos la idea de que la libertad de cátedra es una condición intrínseca del fenómeno enseñanza-aprendizaje, tanto teórico como ético, y en esa medida es una necesidad connatural a la vocación y la tarea universitarias. En este sentido, la libertad de cátedra no representa solo un espacio de inmunidad para la expresión de ideas en el contexto preciso del aula, sino la oportunidad para llevar a cabo una labor colaborativa de búsqueda de la verdad.

Con apoyo en lo anterior sería un error considerar que la libertad de cátedra presupone un modelo de docente que se limita a reproducir de forma indiferente, o si se prefiere inerte, los contenidos propios de un programa académico, sin tomar postura respecto de los mismos, y sin manifestar claramente este posicionamiento; es decir, un docente neutro.

A mi juicio, una perspectiva semejante conduce a que la comunidad académica en la que participa el docente pierda la gran oportunidad de aprovechar los beneficios del pluralismo $^{24}$, y sobre todo de experimentar y atestiguar las virtudes de la honestidad y la coherencia intelectual e incluso, por qué no, la valentía y fortaleza de quien, sabiéndose en un plano de opinión minoritario, insiste en comunicar su perspectiva de la realidad con el afán de enriquecer la perspectiva de todos.

En resumidas cuentas: si la libertad de cátedra se encuentra indudablemente unida a la elaboración comunitaria de la ciencia y es una exigencia para que el académico pueda establecer sus hipótesis, defender sus tesis y exponerlas como tales; su significado ético no se limita a generar las condiciones para hacer ciencia y divulgarla, sino que reclama igualmente las garantías para la acción comprometida con la búsqueda de la verdad.

IV.b El imperativo de corrección política: sus efectos en el ejercicio de la libertad de cátedra y el aprendizaje ético

Quisiera dedicar el último apartado de estas reflexiones al fenómeno denominado "corrección política" 25 . Es sabido que uno de sus efectos morales, concretamente la

\footnotetext{
${ }^{24}$ Como nos recuerda Jaime Nubiola: la pluralidad de opiniones es una consecuencia lógica de la libertad personal y del hecho de que ninguna experiencia humana, por rica que sea, es capaz de agotar la realidad; así, disfrutar del pluralismo implica gozar de una concepción solidaria y multilateral del conocimiento humano, es decir, de que todo lo sabemos entre todos. (Cfr., NUBIOLA, 2007, 22-23).

${ }^{25}$ Un estudio amplio sobre el origen académico de la corrección política y su transformación en imperativo que viene configurando el lenguaje y la forma de pensar contemporánea ha sido elaborado por Ignacio Sánchez Cámara y Fernando Lafuente bajo el título "La apoteosis de lo neutro", Fundación para el análisis y los estudios sociales, Madrid, 1996.
} 
configuración de ciertas pautas discursivas, pueden obstaculizar el ejercicio de la libertad de cátedra ${ }^{26}$ en forma de interdicción lingüística o incluso autocensura. Dentro del marco temático del presente artículo, podría igualmente inhibir el buen desarrollo del aprendizaje ético en el ámbito universitario. Veámoslo con mayor detalle.

Del Merriam-Webster Dictionary aprovecho la siguiente definición para "politically correct": "conforming to a belief that language and practices which could offend political sensibilities (as in matters of sex and race) should be eliminated"27. Es decir, la corrección política es una convicción que justifica un hecho social y lingüístico mediante el cual se busca minimizar la incidencia de tratos discriminatorios (en este caso perpetrados a través del uso de la lengua) en contra de diversos grupos a causa de su origen, raza o sexo, etcétera ${ }^{28}$.

Si bien es cierto que uno de los componentes más relevantes de la violencia cultural se encuentra en el plano de la lengua y el discurso producido con ella ${ }^{29}$ (lo cual pretende ser superado a través de la interdicción linguiística alentada por la corrección política), es igualmente acreditable que, dentro de espacios democráticos y abiertos al debate de ideas, se recurre a la corrección política para justificar actitudes intolerantes. Esto propicia sendas paradojas donde una opinión o convicción que deberían someterse a la libre discusión, propia de los sistemas democráticos, en la práctica se sustraen a ese debate y se imponen como la nueva ortodoxia: un dogma impermeable a la crítica. Lo políticamente correcto se transforma así en un eje axiológico inamovible, en una especie de barrera que anula la opinión contraria o divergente. Se ha señalado, en este sentido, que la corrección política no solo implica la interdicción de ciertos términos, sino que puede conducir a la interdicción de la realidad ${ }^{30}$.

Resulta muy importante señalar que la corrección política es una forma de interdicción lingüística que, a diferencia de la censura, no se encuentra legalmente limitada o controlada, y ahí radica su mayor riesgo tanto para el ejercicio de la libertad de expresión, como para el funcionamiento adecuado de espacios de deliberación pública. Como lo explica Miguel Álvarez Ortega: “su ubicación en un plano comunicativo y no

\footnotetext{
${ }^{26}$ (Cfr., SOMERVILLE, 2015, 58-61)

27 Consulta realizada en: https://www.merriam-webster.com/dictionary/politically\%20correct. (7 de marzo de 2019).

${ }^{28}$ (Cfr., BALLESTEROS, 2000, 175).

${ }^{29}$ (Cfr., GALTUNG, 2003, 18)

${ }^{30}$ (Cfr., ÁLVAREZ, 2010, 338)
} 
directamente normativo tiene como efecto la elisión de la discusión abierta e indisimulada de los posicionamientos sustantivos" (ÁLVARES, 2010, 339).

Aunado a lo anterior, y como adelanté líneas arriba, una de las consecuencias del "régimen de corrección política" ${ }^{31}$ frecuentemente es la generación de la limitación o censura que se impone uno a sí mismo, es decir, la autocensura. En efecto, una vez que se implanta la limitación lingüística y discursiva de la corrección política, se pueden actualizar tres tipos de situaciones: la de los plenos adherentes al consenso ideológico y lingüístico, que no incurren en incorrecciones políticas; la de los convencidos detractores al consenso ideológico y lingüístico, a los que no les importa el efecto que pueda tener sobre ellos la incorrección política; y la de los parcialmente discrepantes del consenso ideológico y lingüístico, pero que temen recibir el efecto de la incorrección política. En este contexto, explica Glenn Loury:

"Por cada acto de discurso aberrante que es castigado por la policía del pensamiento, hay innumerables argumentos críticos, disensos de la verdad adoptada, incómodos reportes de hechos, o desviaciones de pensamiento inconformes que quedan no expresados, o cuya expresión es distorsionada o disfrazada porque los potenciales hablantes temen con razón las consecuencias de la sincera exposición de sus puntos de vista, opiniones y convicciones" (LOURY, 1994, 438).

Cuando, en el contexto de un debate moral, un profesor disidente con una posición políticamente correcta de su comunidad académica se abstenga de defender tesis contrarias a esta posición, bien podría ser un caso de autocensura. ¿Y por qué actuaría de tal manera? Desde luego tiene la alternativa de no hacerlo pero, si lo hace, es que muy probablemente experimenta un temor fundado de encontrarse en riesgo de ser señalado como un sujeto intolerante, prejuicioso, o incapaz de superar cierta aversión obsesiva; en definitiva, como una amenaza al status quo axiológico imperante, y a partir de ahí, otra serie de consecuencias que pueden resultar negativas para el desarrollo normal de una carrera académica, porque una disputa entre opiniones e ideas puede degenerar en un conflicto entre personas.

\footnotetext{
${ }^{31}$ Tomo el término de Glenn Loury quien define un régimen comunicativo donde se ha asentado la corrección política como el patrón equilibrado de expresión e inferencia dentro de una cierta comunidad, donde los receptores de los mensajes imputan cualidades indeseables a los emisores que se expresan en una forma incorrecta y, como resultado, los emisores evitan tales expresiones. (Cfr., LOURY, 1994, 435)
} 
Es ciertamente preocupante que las incidencias de casos en los que se manifiestan ataques contra alumnos o académicos por manifestar lo que a su juicio representa un acierto o un error son cada vez mayores ${ }^{32}$. No solo se menoscaban y vulneran derechos humanos de quienes se ven afectados por los efectos de la incorrección política en la que incurren, sino que la calidad del espacio público se debilita como ámbito para comprender mejor, entre todos, la realidad; el mismo efecto puede ocurrir al aula universitaria que pierde capacidad para ser un ambiente propicio para el aprendizaje ético que fomente la madurez de quienes ahí participan.

En este sentido, creo que lo que corresponde a un universitario comprometido con los valores que inspiran la actividad académica seria y la experiencia universitaria genuina, es una crítica y denuncia respecto de la pretensión de que ciertas convicciones puedan escapar al debate amplio y respetuoso, incluido por supuesto el foro académico, mediante la denigración o la exclusión de los opositores. Más aun, el docente comprometido realmente con su vocación, debe hacer el esfuerzo por exponer sus puntos de vista, previo cumplimiento de las condiciones de la imparcialidad, y así incorporarse, junto con sus alumnos, "en la dinámica de una inteligencia viviente, de un logos común, que convoca a la búsqueda de la verdad en libertad, esencia misma de las corporaciones académicas" (LLANO, 2016, 213).

En resumidas cuentas, el régimen de corrección política puede amenazar o incluso cancelar la posibilidad del diálogo racional, propio del ámbito académico. Pero sobre todo, puede obstaculizar la oportunidad para que el docente muestre, con su conducta, la coherencia de pensamiento, la honestidad intelectual, y otra serie de virtudes que serían indispensables para configurar un ambiente adecuado para el aprendizaje ético.

\section{Conclusiones}

Llegados a este punto deseo postular algunas ideas que, en todo caso, serán un recuento de lo que he expuesto hasta ahora.

Primera. Iniciativas intelectuales como las propuestas por Martínez, Buxarrais y Esteban deben, a mi juicio, ser atendidas. Considerar que la experiencia universitaria puede albergar las condiciones para el crecimiento ético de quienes participan en ella es un acierto: profesores y alumnos pueden llevar a cabo un aprendizaje ético como docentes y dicentes; de manera colaborativa pueden hacer del contexto académico un ambiente

\footnotetext{
${ }^{32}$ Un reporte amplio de casos ocurridos en Canadá puede encontrarse en: (SOMERVILLE, 2015, 58-61).
} 
propicio para el compromiso radical con actitudes respetuosas de la dignidad de la persona.

Segunda. En este renovado enfoque de la vida universitaria, el primer interpelado es el docente. Su vocación da mayor fruto cuando se toma conciencia del "contrato moral" implícito en la generación y transmisión de la ciencia. Así mismo cabe hacer hincapié en que para evitar la beligerancia y el dominio del profesor sobre el alumno, es imperativa e inexcusable una actitud imparcial, aunque no necesariamente sea exigible la neutralidad.

Tercera. La libertad de cátedra ha acompañado a la Universidad en su moderno devenir histórico, si bien con importantes matices y significados diversos en cada momento. Ahora tenemos la ocasión de redescubrir su sentido práctico, y sobre todo de defender su ejercicio responsable frente a interpretaciones manifiestamente equivocadas respecto de los cimientos y de la praxis democrática, tal y como se viene perfilando a través de la incidencia de la corrección política. Una libertad de cátedra reconocida y ejercida facilita la realización de los múltiples beneficios que supone la pluralidad de ideas y opiniones, y al mismo tiempo representa una garantía para que el docente asuma el importante papel que le corresponde en el marco de la pedagogía cívica y el aprendizaje ético.

\section{Bibliografía}

AGUADO I CUDOLÀ, V. (2010). Libertad de cátedra, organización y planificación docente en la prestación del servicio público de enseñanza universitaria: el nuevo contexto del Espacio Europeo de Educación Superior. Revista de Educación y Derecho, núm. 2, 1-15.

AGUILÓ, J. (2009). Dos concepciones de la ética judicial. Doxa. Cuadernos de Filosofía del Derecho, núm. 32, 525-540.

ÁLVAREZ, M. (2010). Repercusiones jurídico-políticas de la interdicción lingüística: tabú, censura y corrección política. Estudios de Deusto, vol. 58/2, 32-341.

APARISI, A. (2006). Ética y deontología para juristas. Pamplona: EUNSA.

BALLESTER, M. (2012). "Lo políticamente correcto o el acoso a la libertad". Cuadernos de pensamiento político, núm. 34, 171-201. 
BALlESTEROS, J. (2000). Postmodernidad: decadencia o resistencia. Madrid: Tecnos.

BAUMAN, Z. (2005). Ética posmoderna. México: Siglo XXI.

GALTUNG, J. (2003). Violencia cultural. Gernika-Lumo: Gernika Gogoratuz.

JONAS, H. (1995). El principio de responsabilidad. Ensayo de una ética para la civilización tecnológica. Barcelona: Herder.

LLANO, A. (1999). Humanismo cívico. Barcelona: Ariel.

LOURY, G. (1994). Self-censorship in public discourse: A theory of political correctness and related phenomena. Rationality and Society, núm. 6, 428-461.

MADRID, R. (2013). El derecho a la libertad de cátedra y el concepto de universidad. Revista Chilena de Derecho, vol. 40, núm. 1, 355-371.

MARTÍNEZ, M. et al. (2002). La Universidad como espacio de aprendizaje ético. Revista Iberoamericana de Educación, núm. 32, 17-42.

NUBIOLA, J. (2007). Pensar en libertad. Pamplona: EUNSA.

SÁNCHEZ, I. y LAFUENTE, F. (1996). La apoteosis de lo neutro. Madrid: Fundación para el análisis y los estudios sociales, Madrid.

SERNA, P. (2006). Filosofía del derecho y paradigmas epistemológicos. De la crisis del positivismo jurídico a las teorías de la argumentación jurídica y sus problemas. México: Porrúa.

SMEND, R. (2005). Ensayos sobre la libertad de expresión, ciencia y cátedra como derecho fundamental y el Tribunal Constitucional Alemán. México: Instituto de Investigación Jurídicas/UNAM.

SOMERVILLE, M. (2015). Bird on an ethics wire. Battles about values in the cultural wars. Montreal: McGill-Queen’s University Press.

SPAEMANN, R. (2000). "Normas morales y orden jurídico", Persona y Derecho, Núm. 42, 109-129.

TRUJILLO, I. (2007). Imparcialidad. México: Instituto de Investigaciones Jurídicas de la UNAM. 
HUGO SAÚL RAMÍREZ GARCÍA. Ética y experiencia universitaria: el papel de la libertad de cátedra en el

VIOLA, F. (1998). De la naturaleza a los derechos. Los lugares de la ética contemporánea. Granada: Comares. 